\author{
Journal of Critical Race Inquiry \\ Vol. 2, No. 2 (2015) p. 1
}

\title{
'Farewell' from the Outgoing Editor
}

\author{
Barrington Walker \\ Department of History, Queen's University
}

It has been a pleasure to serve as the editor for the Journal of Critical Race Inquiry since its inception. This journal has emerged as an important venue for the publication of high quality research in the field of critical race studies. It has served as a home for the work of scholars from a range of disciplines in the humanities and social sciences. This has been crucial because critical race scholars working in fields as diverse as political science, sociology, geography, history and epidemiology often find that they have the common struggle of chafing against the received wisdom of their fields. The critical scholar of race often finds she has the burdens of teaching "first principles" to the woefully uninitiated, establishing the worthiness of her research to gatekeepers who are often highly skeptical of it, producing scholarship of high quality and hoping that editors will have the sensitivity to find knowledgeable and sympathetic readers to assess her work (and even this is contingent upon the editor having a modicum of knowledge about the field). I believe that the JCRI has addressed these issues and more importantly, provided a vital space where the field of Critical Race Studies can continue to flourish and grow.

I leave the journal in capable hands. Dr. Leela Viswanathan and Dr. Scott Morgensen are both highly respected scholars in the field who will be able to not only continue the course that has been charted over the past years with but take it to new heights. While I am saddened by my departure, I know that the best days are ahead for JCRI and it is time to turn it over to scholars with energy, enthusiasm and a renewed vision for its future. 